So we have one story, wildly reported, and by appearing in print gaining the substance of fact. What is a fact is that all the frequent discussion of this case has not resulted in the publication of one other case. It is important, therefore, that everyone should know the story so that inaccuracies can be refuted as soon as they are uttered, not after they have been published.

My thanks go to Mr Philip Cordrey, Contact Lenses Manufacturing Ltd, for supplying me with the correspondence which is the substance of this letter.

H J KeRSLEY

President-Elect,

London British Contact Lens Association

'Report to the Royal Society for the Prevention of Accidents from the Consultant Ophthalmic Surgeon
to the Department of Employment, November 1973 .

Ruben, $M$, open letter on behalf of the Contact Lens Society, February 1976.

Circular to employees of Thames Valley Water Authority from the Senior Resident Engineer,

16 July 1975.
fournal of Occupational Safety and Health, October

\section{Barbiturates and fractures}

SiR,-Drs J B and E T Macdonald (20 August, p 483) have shown a highly significant correlation between the ingestion of barbiturate hypnotics and nocturnal fractures of the femur. It is curious that none of the patients sustaining fractures in the afternoon were on barbiturates; it would be expected that fractures would occur with an equal incidence in patients on barbiturates and those on non-barbiturate hypnotics if neither drug affected the likelihood of fractures occurring at this time. Either barbiturates protect against afternoon fractures (which seems unlikely) or other hypnotics predispose to fractures occurring in the morning and afternoon. Unfortunately there is no comparison of the temporal incidence of fractures in patients not taking hypnotics (a reflection, perhaps, of the overuse of these drugs in the elderly), so that neither intriguing possibility can be explored. It would also be interesting to know if there was a significant correlation between non-barbiturate hypnotic use and frequent falls, as there was with barbiturate use.

There is a high incidence of osteomalacia in elderly patients with fractures of the femur ${ }^{1}$; and osteomalacia is a recognised complication of the chronic ingestion of long-acting anticonvulsant barbiturates" (for example, phenobarbitone), which reduce the level of circulating 25-hydroxycholecalciferol ${ }^{3}$ by inducing hepatic microsomal enzymes. This effect is likely to be of particular significance in the elderly, whose nutritional status with respect to vitamin $\mathrm{D}$ may already be less than ideal. That this may occur with other barbiturates (those with shorter plasma half lives, used as hypnotics) is suggested by the results of a recent survey in which patients taking these drugs were found to have lower serum calcium concentrations than controls. ${ }^{4}$ Though there was no significant increase in serum alkaline phosphatase activity in these patients and only $26.4 \%$ of the patients with fractures in the Macdonalds' survey were taking barbiturates in comparison with from $41 \%$ to $51 \%$ of newly referred outpatients (the increase between 1973 and 1976 is itself a worrying trend), the possibility of an increased incidence of osteo- malacia is another reason for not prescribing barbiturate hypnotics in the elderly.

William MaRSHali

Lewisham Hospital,

'Jenkins, D H R, et al, fournal of Bone and foint Surgery, 1973, 55B, 575 .

British Medical fournal, 1970, 4, 69 ahn, T J, et al, New England fournal of Medicine,

$1977,53,212$. al, Postgraduate Medical fournal,

SIR,-Drs J B and E T Macdonald (20 August, p 483) are to be congratulated on their excel lent article. Should one prescribe barbiturates other than for epilepsy, then we initiate the hazard of addiction and poisoning. So often it is thought that our patient is the exception to the rule. It is highly dangerous to imagine any exceptions to this rule. Confusion, even dementia and terminal illness, are not always recognised as being related to chronic barbiturate administration.

Alas, I doubt whether this informative article will affect our prescribing. Fortunately a summary appeared in The Times of 19 August and this may be more effective. An American lawyer pointed the article out to me and the sooner relatives query every barbiturate prescription the sooner this problem will decrease.

Anthony Churcher

Eastbourne, Sussex

\section{Superior vena caval obstruction} complicating fibreoptic gastroscopy

SIR,-The case reported by $\mathrm{Dr} J$ Dawson (6 August, p 368) raises several interesting points.

Although the complication was unavoidable in his patient, its occurrence emphasises the need to avoid immediate endoscopy in patient with mediastinal obstruction and to wait until radiotherapy has reduced the obstruction. There is little urgency for a tissue diagnosis, as almost all these patients have carcinoma of the bronchus, though $2-3 \%$ have other tumours, and benign causes of superior vena caval obstruction are now very rare. ${ }^{1}$

The second point is his comment that superior vena caval obstruction is an uncommon complication of carcinoma of the bronchus. In fact it occurs in $10-15 \%$ of these patients-that is, $3000-4500$ patients every year in Britain. Its incidence is comparable to that of carcinoma of the bladder or of the oesophagus.

Lastly, although pain is often a feature of carcinoma of the bronchus, it is not a specific feature of superior vena caval obstruction.

\section{Department of Radiotherapy and \\ Department \\ Charing Cross Hospital \\ London W6} N HOWARD

Howard, N, Mediastinal Obstruction in Lung Cancer. London and Edinburgh, Livingstone, 1967.

\section{Nocturnal infusions}

SIR,-I was pleased to see the paper by $M$ I H Frazer and others (23 July, p 232) confirming that the incidence of infusion phlebitis is directly related to the duration of infusion. However, as pointed out previously, ${ }^{1}$ the pre- vention of thrombophlebitis is not the only reason for taking down infusions at night. Keeping infusions going overnight is rarely necessary as well as being unphysiological and potentially dangerous. At night fewer nurses are on duty and the darkness makes it difficult to keep an accurate check on infusions. With no nocturnal infusion the patient sleeps better - fewer checks by the nurses are required and the need to pass urine is reduced-and there is less chance of overloading the patient with fluid. In addition other patients in the ward have a more peaceful night and the nurses are free to attend to other duties.

The disadvantages of such a policy are the cost of extra infusion sets and the fact that housemen will have to put up infusions more frequently. However, as the infusions have to run for only 12-18 hours, smaller needles, which are easier to insert, can be used. Surely more peaceful nights for all patients in the ward and fewer complications more than compensate for these minor disadvantages. An added bonus for the houseman is that he is not disturbed at night because of trouble with his infusions.

In short, I maintain that except for intensive care and for the first postoperative night nocturnal infusions are rarely indicated, are potentially dangerous, and are unfair to our patients and our nurses.

Guy's Hospital,

H G STURZAKER

${ }^{1}$ Sturzaker, H G, British Medical fournal, 1975, 4, 163.

\section{Zinc again}

SIR,-Your leading article (11 June, p 1493) comments on two papers which describe the apparent beneficial effects of oral zinc sulphate on acne vulgaris. ${ }^{12}$ Although "it is far too early to assess the full meaning of the findings," you hint that this work should be expanded and confirmed. However, we feel that the following comments are warranted before large-scale trials using oral zinc sulphate are started.

In their clinical study Michaëlsson et $a l^{1}$ included a placebo group of 14 patients but "for ethical reasons" added oral zinc sulphate to their treatment after only four weeks of the 12-week study. With a placebo effect of between 19 and $56 \%$ improvement in acne vulgaris we feel it would not have been unethical to continue placebo until 12 weeks and provide data for meaningful analysis.

Our second point concerns the dosage of oral zinc sulphate. In Michaëlsson's studies each patient received a total daily dose of $600 \mathrm{mg}$ effervescent zinc sulphate, equivalent to $135 \mathrm{mg}$ of ionic zinc, which is many times the US National Research Committee's recommended dietary allowance of $15 \mathrm{mg}$ ionic zinc per day. Although toxic side effects from oral zinc sulphate are said to be rare,,$^{3-5}$ acute zinc toxicity, manifest as nausea, vomiting, diarrhoea, and haemolytic anaemia, has been documented as occurring in patients with chronic renal failure receiving intermittent haemodialysis. ${ }^{6} 7$ Acute toxicity occurred with venous plasma levels of $45 \mu \mathrm{mol} / 1(294 \mu \mathrm{g} /$ $100 \mathrm{ml}$ ). Unpublished work by Glover has shown that one 220-mg capsule of zinc sulphate causes the venous plasma zinc concentration to rise from a normal fasting value of 15.3 $\mu \mathrm{mol} / \mathrm{l}(100 \mu \mathrm{g} / 100 \mathrm{ml})$ to an average value of $40 \cdot 1 \mu \mathrm{mol} / 1(262 \mu \mathrm{g} / 100 \mathrm{ml})$ at $1 \frac{1}{2}-3$ hours. Several of the volunteers in this study became 
nauseated and vomited. In addition to these well-known local irritant effects of zinc sulphate on the gastrointestinal tract, consideration must be given to potentially toxic side effects of the large and unphysiological concentrations of zinc achieved in human plasma with the recommended zinc sulphate regimen.

In the light of these observations we fee that the current recommendations to treat acne vulgaris with $220 \mathrm{mg}$ of zinc sulphate thrice daily is unwarranted owing to the excess quantity of zinc ion absorbed. There is an urgent need to investigate the dose effective ness of zinc sulphate supplementation not only in patients with acne vulgaris but also in the various other conditions for which zinc has been recommended. This is being done in this department.

Stuart Cunningham Glover Department of Medicine, Aberdeen University

MARION I WhITE

Aberdeen Royal Infirmary

Aberdeen

Michaëlsson, G, Juhlin, L, and Vahlquist, A, Archives of Dermatology, 1977, 113, 31

Michaëlsson, G, Vahlquist, A, and Juhlin, L, British Journal of Dermatology, 1977, 96, 283.

Husain, S L, Lancet, $1969,1,1069$.

.

Clinical Applications of Zinc Metabolism, Cleveland 1971.

' Petrie, J J B, and Row, P G, Lancet, 1977, 1, 1178

Gallery, E D M, Bloomfield, J, and Dixon, S R,

British Medical fournal, 1972, 4, 331

Management of medicines in residential homes

SIR,-It is interesting to compare the advice in DHSS circular 18/69 issued in December 1969 with that in the annex to the "Memorandum of Guidance, Residential Homes for the Elderly," issued in June 1977. I think it shows a rising standard of care in the handling of medicines and I would like to draw attention to particular areas of development so that I can indicate where I think what we do still falls short of excellence.

(1) The 1977 memorandum makes mention of the fact that dispensed medicines are now labelled with details of their contents - that is, NP labelling has been achieved. This is a boon to the staff of homes, who formerly struggled with a chaotic mass of unidentified drug containers bearing unhelpful legends such as "The Tablets" or "The Capsules." The memorandum fails to state that it is now required by law that the date of dispensing appears on drug containers. This is also a most useful advance.

(2) Recording arrangements are described in far more detail in the 1977 memorandum than in the 1969 circular, with provision for a resident's care record document and a medication record. The problem here should not be underestimated. We can have 50 or more residents in a home, most on drugs, many on several different preparations to be administered several times a day. To achieve the prescriber's intentions exactly every day for every patient is a formidable task. Clearly the staff giving out medicines need to be able to see at a glance exactly what is required at each medicine round and the doctor will find it helpful to see the practice records of drug therapy duplicated in the residential home when he attends his patient there. Absolute accuracy is paramount. The care record document and the medication record are the counterparts of the prescribing and recording sheets recom- mended in the Gillies Report 1970 on "Measures for Controlling Drugs on the Wards," and widely adopted in hospitals since then. There are, alas, important differences between the circumstances applying in residential homes and those in hospital and they all act against the patients' interests.

Firstly, in hospital the nurse works from what the doctor has written. The prescription becomes the instruction to the nurse. In a residential home the drug is prescribed on form FP10 and, if the doctor has visited the resident in the home, the head of the home briefly has sight of the prescription before it goes to the pharmacy for dispensing. If the prescription is written at the surgery, and most are, the head of the home may not see it at all and must enter details on the care record documen from the drug container labels. The person givin out medicines works from a twice-transcribed prescription.

Secondly, opportunities for communication about drug therapy between the prescriber and the head of the home are less frequent in the residential home than in the hospital and uncertainty can easily arise as to whether a drug is still current or has been cancelled.

(3) The ideal situation would be for the doctor to see the care record document each time he writes a prescription and for him to enter on it details of the drugs he has prescribed and to make cancellations. This is administratively awkward and the memorandum delegates this duty to the head of the home and suggests meekly that "doctors may consider it desirable to initial these entries." (The author of the memorandum obviously thinks doctors are very fierce creatures and need to be handled ever so gently.) To place the onus of avoiding transcription errors etc entirely on a lay person seems to me surprising. In hospitals the three professions of medicine, nursing, and pharmacy co-operate to the benefit of patients safety; we should aim to achieve a similar situation in residential homes.

E R TAlletT Lancashire Area Pharmaceutical

Burnley General Hospital,
Burnley, Lancs

\section{Breakfast and Crohn's disease}

SIR,-Dr A H James (9 April, p 943) reported that $67.6 \%$ of 34 patients with Crohn's disease were regular consumers of cornflakes at breakfast when their symptoms began compared with 17 of $68(25 \%)$ controls. The validity of the comparison depends in part upon the control data and as we have collected dietary information in several epidemiological studies we have looked at the prevalence of cornflakes consumption in two of these. The first was carried out in 1966 on a sample $(n=220)$ of the employees of a large pharmaceutical firm ${ }^{1}$ and the second over the past two years on a sample $(n=142)$ of the employees of the Greater London Council and Inner London Education Authority. As there were no systematic differences associated with age or sex the results were combined in each case. The proportion of the whole sample eating cornflakes was $24 \%$ in 1966 and $32 \%$ in 1976-7.

Our results are similar to those in $\mathrm{Dr}$ James's control group who were also questioned about current habits. His patient group was, however, asked to recall habits of some years earlier, always difficult to validate. It may also be relevant that dietary advice to patients with Crohn's disease has traditionally been a bland diet, low in roughage-thus from Davidson and Passmore" : "Breakfast-strained porridge with milk from allowance or small helping of crisp cereal (avoiding those containing bran, nuts or fruit)...".

B J THOMAS

R J JARRETT

H KEEN

Department of Medicine,

Guy's Hospital,

'Boyns, D R, et al, British Medical fournal, 1969, 1, 595 Davidson, S, and Passmore, R, Human Nutrition and Dietetics, 3rd edn, p 802 . Edinburgh, Livingstone, 1966.

\section{Amendment of the Abortion Act}

SIR,-Further to the discussion in the Annual Representative Meeting of the BMA, it is clear that although the Benyon Bill is probably defeated, there will, in future, be further efforts to restrict the Abortion Act of 1967. Members of Parliament have been deluged in the past few years with letters from people who are anti-abortion and who are very firm in their views and very well organised. This has, I feel, given most members of Parliament a biased impression about the feelings of the community in general. If patients who are recommended for legal terminations of pregnancy could be told of this by their doctors when recommending such a course perhaps more of them will feel inclined to write to their members of Parliament to tell their views so that these members could get a more balanced impression of the feelings of the community which they serve.

Romford, Essex

KATHLEEN Frith

\section{Breast size and cancer}

SIR,-Recently Professor B N Catchpole (19 March, p 776) and Dr A J Robertson and others (14 May, p 1283) wrote letters about the lack of information on breast size in relation to cancer.

We are currently conducting a case-control study of breast cancer in which the women are queried with respect to the size of their brassière. Thus far 85 cases have been compared with 170 controls, matched by age and race. No differences were noted. Thirteen cases $(15.3 \%)$ and 27 controls $(15.9 \%)$ had a breast cup size of $\mathrm{C}$ or larger with at least a 34 -in $(83 \cdot 36-\mathrm{cm})$ bustline. In two earlier studies $^{12}$ the breast sizes of cases and controls were also very similar.

TOMIO Hirohata

ABRAHAM M Y NOMURA

LAURENCE N KOLONEL

Epidemiology Unit,

Cancer Center of Hawaii,

University of Hawaii,

${ }^{1}$ Wynder, E L, Bross, I J, and Hirayama, T, Cancer, $1960,13,559$. Valaoras, V G, et al, International fournal of Cancer,
1969, 4, 350.

\section{Reversal of sterilisation}

SIR,-It is difficult to know what conclusions one can reach in a study of 103 women who asked for reversal of sterilisation ( $\mathrm{Mr} \mathrm{R} \mathrm{M} \mathrm{L}$ Winston, 30 July, p 305) when there are no data about the numbers and characteristics of the women who were sterilised and have 